\title{
Adubação nitrogenada de cobertura no feijoeiro de inverno- primavera em três sistemas de cultivo
}

\section{Nitrogen topdressing on common bean cropped in winter-spring in three cropping systems}

\author{
Ciro Franco Fiorentin ${ }^{1}$; Leandro Borges Lemos ${ }^{2}$; \\ Celso Antonio Jardim ${ }^{3}$; Domingos Fornasieri Filho ${ }^{4^{*}}$
}

\section{Resumo}

O objetivo do trabalho foi avaliar a influência da adubação nitrogenada em cobertura no feijoeiro irrigado (inverno-primavera), no primeiro ano de implantação do sistema de semeadura direta. O delineamento experimental utilizado foi o de parcelas subdivididas, com três repetições, dispostos em blocos casualizados. As parcelas foram formadas por três formas de cobertura do solo, milho-grão, milhogrão consorciado com Brachiaria ruziziensis e apenas B. ruziziensis. As subparcelas foram formadas por cinco doses de adubação nitrogenada em cobertura $\left(0,40,80,120\right.$ e $\left.160 \mathrm{~kg} \mathrm{ha}^{-1}\right)$, utilizando a uréia como fonte de nitrogênio. Foi determinada a massa seca da palhada presente como cobertura do solo anteriormente à semeadura da cultura do feijoeiro, o momento do florescimento pleno, o teor foliar de nitrogênio total, a massa de 100 grãos, a produtividade de grãos, a renda de beneficiamento, os atributos químicos do solo e a análise econômica da produção de grãos de feijão. Verificou-se que a produtividade de grãos de feijão em sucessão ao milho-grão foi influenciada positivamente pela adubação nitrogenada, sendo economicamente viável apenas quando fornecido $160 \mathrm{~kg} \mathrm{ha}^{-1}$ de nitrogênio e que o uso do consórcio entre milho-grão e $B$. ruziziensis é a melhor opção quando o feijoeiro é semeado em sucessão. Palavras-chave: Phaseolus vulgaris, Brachiaria ruziziensis, Zea mays L., sistema de semeadura direta

\begin{abstract}
The aim of this study was to evaluate the nitrogen topdressing influence in common bean irrigated (winter-spring), in the first year of no tillage implementation. The experimental design was split-plot with three replications in randomized blocks. The plots were formed by three types of ground cover, corn-grain, corn-grain intercropped with Brachiaria ruziziensis and only B. ruziziensis. The subplots were formed by five doses of nitrogen topdressing $\left(0,40,80,120\right.$ and $\left.160 \mathrm{~kg} \mathrm{ha}^{-1}\right)$, using urea as nitrogen source. It was determined the dry mass of residue present as ground cover, the full flowering time, the leaf nitrogen content, the 100 grains mass, the grain yield, the processing income, the chemical soil properties and economic analysis of common bean grain yield. It was found the common bean grain productivity in succession to corn-grain was positively influenced by nitrogen fertilization, showing it is economically viable only when given $160 \mathrm{~kg} \mathrm{ha}^{-1}$ of nitrogen and the intercropping corn-grain and $B$. ruziziensis use is the best option when the common bean is sown in succession.
\end{abstract}

Key words: Phaseolus vulgaris, Brachiaria ruziziensis, Zea mays L., no tillage system

\footnotetext{
${ }^{1}$ Mestre em Agronomia, Produção Vegetal do Dept ${ }^{\circ}$ de Produção Vegetal, Fitotecnia, Faculdade de Ciências Agrárias e Veterinárias, FCAV, Universidade Estadual Paulista Júlio de Mesquita Filho, UNESP. Jaboticabal, SP. E-mail: cifiorentin@yahoo.com.br

2 Prof. Dr. Assistente do Dept ${ }^{\circ}$ de Produção Vegetal, Fitotecnia, FCAV/UNESP, Jaboticabal, SP. E-mail: leandrobl@fcav.unesp.br

${ }^{3}$ Doutorando em Agronomia, Produção Vegetal, Dept ${ }^{\circ}$ de Produção Vegetal, Fitotecnia, FCAV/UNESP, Jaboticabal, SP. E-mail: cejardim@yahoo.com.br

${ }^{4}$ Prof. Titular do Dept ${ }^{\circ}$ de Produção Vegetal, Fitotecnia, FCAV/UNESP, Jaboticabal, SP. E-mail: fornasieri@fcav.unesp.br

* Autor para correspondência
} 


\section{Introdução}

A cultura do feijoeiro irrigado é uma importante opção econômica na entressafra para as regiões Centro-Oeste e Sudeste com clima tipo Aw (tropical úmido com estação chuvosa no verão e seca no inverno) segundo classificação de Köppen. Porém nessas regiões, o estabelecimento da cultura no sistema de semeadura direta é dificultado, pois altas temperaturas, associadas à elevada umidade do solo no verão, favorece a rápida decomposição da palhada, dificultando sua formação e/ou a manutenção na superfície do solo (FREIXO et al., 2002).

Para viabilizar o sistema de semeadura direta é necessária a utilização de plantas de cobertura que possibilitem, além da produção e manutenção de elevada quantidade de palhada sobre o solo, acréscimos de produtividade para as culturas em sucessão. Para isso, uma das opções seria o consórcio de culturas produtoras de grãos (milho, por exemplo) e gramíneas perenes com elevado potencial para formação de palhada e de ciclagem dos nutrientes presentes nas camadas mais profundas do solo (SILVA; MIELNICZUK, 1997). O aporte de palhada na superfície do solo ao longo dos anos proporciona significativa melhora da qualidade do solo, tanto física, quanto química e biológica (LOPES et al., 2004b).

Por sua vez, o feijoeiro, quando semeado no período da entressafra, proporciona elevado retorno financeiro, por ser um período em que o produto alcança maiores preços. Contudo, embora apresente a capacidade de fixação biológica do $\mathrm{N}_{2}$ atmosférico, tem apresentado elevadas respostas ao fornecimento de $\mathrm{N}$ mineral, o que contribui para a elevação dos custos de produção (BINOTTI et al., 2009).

Silva et al. (2009) citam que a palhada da cultura do milho pode ter uma relação de até $71 / 1$ ao final de seu ciclo. Já Torres et al. (2005) verificaram que em dois anos agrícolas, a relação $\mathrm{C} / \mathrm{N}$ da $B$. brizantha foi de 16,1 e 19,6. Lopes et al. (2004b) argumenta que em solos cobertos por palhada com relação C/N superior a 30/1, o crescimento da população microbiana é limitada, ocorrendo imobilização do $\mathrm{N}$ presente no solo, enquanto que a mineralização é favorecida na palhada com relação $\mathrm{C} / \mathrm{N}$ abaixo de 20/1, até tornar-se relativamente estável em torno de $10 / 1$.

O objetivo do trabalho foi avaliar a influência da palhada proveniente de culturas antecessoras e da adubação nitrogenada em cobertura no feijoeiro irrigado no primeiro ano de implantação do sistema de semeadura direta.

\section{Material e Métodos}

O trabalho foi conduzido em Jaboticabal, SP, no Campus da Faculdade de Ciências Agrárias e Veterinárias da UNESP, no ano agrícola 2009/10. A área está localizada a $21^{\circ} 14^{\prime} 33^{\prime \prime} \mathrm{S}$ de latitude, $48^{\circ}$ $17^{\prime} 10^{\prime \prime} \mathrm{W}$ de longitude e a 565 metros de altitude. De acordo com a classificação de Köppen, o clima predominante na região é do tipo Aw, tropical úmido com estação chuvosa no verão e seca no inverno.

O solo é do tipo Latossolo Vermelho eutroférrico, textura argilosa, apresentando em média $533 \mathrm{~g} \mathrm{~kg}^{-1}$ de argila, $193 \mathrm{~g} \mathrm{~kg}^{-1}$ de silte e $274 \mathrm{~g} \mathrm{~kg}^{-1}$ de areia. A análise química do solo foi realizada de acordo com metodologia descrita por Raij et al. (2001). Os valores obtidos foram: $\mathrm{pH}\left(\mathrm{CaCl}_{2}\right): 5,2 ;$ M.O. $\left(\mathrm{g} \mathrm{dm}^{-}\right.$ $\left.{ }^{3}\right)$ : 21; P-resina $\left(\mathrm{mg} \mathrm{dm}^{-3}\right): 56 ; \mathrm{H}+\mathrm{Al} ; \mathrm{K} ; \mathrm{Ca} ; \mathrm{Mg}$; SB; CTC (mmol $\left.\mathrm{dm}^{-3}\right): 25 ; 4,4 ; 24 ; 10 ; 38,4 ; 63,4$ respectivamente e saturação por bases de $61 \%$.

Antes da implantação do experimento a área foi cultivada por no mínimo 15 anos com culturas anuais (milho no verão) em sistema convencional e na entressafra foi mantida em pousio. Para a implantação do experimento realizou-se a escarificação mecânica, seguida de aração com arado de discos e duas gradagens com grade niveladora.

O delineamento experimental utilizado foi o de parcelas subdivididas, com três repetições, dispostos em blocos casualizados. As parcelas 
foram formadas por três sistemas de cultivo no verão: milho-grão, milho-grão consorciado com Brachiaria ruziziensis e apenas B. ruziziensis sem que houvesse pastejo na área. As subparcelas foram formadas por cinco doses de adubação nitrogenada em cobertura no feijoeiro $(0,40,80,120$ e $160 \mathrm{~kg}$ $\left.\mathrm{ha}^{-1}\right)$, utilizando a uréia como fonte de $\mathrm{N}$.

A semeadura do milho foi realizada no dia 19/11/2008. Foi utilizado o híbrido simples DKB 390, no espaçamento de $90 \mathrm{~cm}$ entrelinhas. A adubação base foi $30 \mathrm{~kg} \mathrm{ha}^{-1}$ de $\mathrm{N}, 50 \mathrm{~kg} \mathrm{ha}^{-1}$ de $\mathrm{P}_{2} \mathrm{O}_{5}$ e $50 \mathrm{~kg} \mathrm{ha}^{-1}$ de $\mathrm{K}_{2} \mathrm{O}$, e em cobertura $140 \mathrm{~kg} \mathrm{ha}^{-1}$ de $\mathrm{N}$ (uréia) com o milho no estádio $\mathrm{V}_{6}(15 / 12 / 08)$. A densidade populacional final foi próxima a 60.000 plantas ha ${ }^{-1}$. A B. ruziziensis quando consorciada com milho-grão foi semeada na densidade de 300 sementes viáveis por $\mathrm{m}^{2}$, imediatamente após a adubação nitrogenada em cobertura no milho-grão. A semeadura foi realizada na profundidade de $2 \mathrm{~cm}$, sendo alocadas duas linhas em cada entrelinha do milho-grão. A B. ruziziensis não consorciada foi semeada no mesmo dia àquela consorciada com o milho-grão, em linhas espaçadas de $22 \mathrm{~cm}$, com 300 sementes viáveis por $\mathrm{m}^{2}$, omitindo-se a aplicação de fertilizantes. Efetuou-se a colheita mecânica dos grãos de milho em 30/05/09, deixando os restos culturais sobre o solo em pousio. Em 03/07/09 a vegetação da área experimental foi dessecada com glifosato na dose de $1.800 \mathrm{~g} \mathrm{ha}^{-1}$ de equivalente ácido.

O feijoeiro (Phaseolus vulgaris L.) cultivar Pérola foi semeado após 30 dias da dessecação da área. A quantidade de sementes utilizadas foi calculada para obtenção de 266.000 plantas ha ${ }^{-1}$. Cada subparcela foi composta por dez linhas de feijoeiro, espaçadas a 0,45 metros e com cinco metros de comprimento, considerando como área útil as oito linhas centrais, desprezando-se 0,5 metros em cada extremidade. A adubação de semeadura foi $200 \mathrm{~kg} \mathrm{ha}^{-1}$ do formulado 5-15-10. A adubação de cobertura do feijoeiro foi realizada aplicando-se a uréia em filete contínuo a dez $\mathrm{cm}$ da linha da cultura sem incorporação, no estádio de desenvolvimento $\mathrm{V}_{4-4}$ (FERNÁNDEZ; GEPTS; LÓPES, 1985).
Imediatamente após a adubação, a área foi irrigada por aspersão até a obtenção de uma lâmina de água de $30 \mathrm{~mm}$ para incorporação da uréia no solo. Isso se faz necessário pelo fato do fertilizante apresentar potencial de perda de $\mathrm{N}_{-} \mathrm{NH}_{3}$ por volatilização. Durante o ciclo da cultura, a irrigação foi realizada por aspersão convencional, cujo manejo foi baseado no método do tanque "Classe A" parametrizado pela FAO. A quantidade de água fornecida foi determinada pelo método do balanço hídrico climatológico simplificado (LOPES et al., 2004a).

As avaliações realizadas foram: a) a determinação da massa seca da palhada presente como cobertura do solo aos dez dias antes da semeadura do feijoeiro, utilizado quadro de madeira com dimensões internas de $0,5 \times 0,5 \mathrm{~m}$, sendo as amostras colhidas submetidas à lavagem e secas em estufa de ventilação forçada de ar a $65-70^{\circ} \mathrm{C}$ até massa constante; b) o momento (em dias após a emergência) do florescimento mediante a observação da presença da primeira flor aberta em $50 \%$ das plantas de cada subparcela (FERNÁNDEZ; GEPTS; LÓPES, 1985); c) o teor foliar de nitrogênio total (NT) de acordo com método descrito por Bataglia et al. (1983), coletando-se a terceira folha trifoliolada com pecíolo, do terço médio, no florescimento da cultura (AMBROSANO et al., 1997); d) a massa de 100 grãos, coletando-se numa das linhas da área útil dez plantas consecutivas e, posteriormente, quantificando-a através da contagem de 100 grãos com quatro repetições; e) a produtividade de grãos ( $\mathrm{kg} \mathrm{ha}^{-1}$ a $13 \%$ de umidade), obtida após colheita das três linhas centrais de cada subparcela. A colheita foi realizada em 11/11/09 mediante o arranquio manual das plantas maturas, seguida de trilha mecanizada com colhedora de parcela; f) a renda de beneficiamento dos grãos colhidos, mediante sua passagem num conjunto de peneiras de crivos oblongos 11/64" x 3/4, 12/64" x 3/4, 13/64" x 3/4 e 14/64" x 3/4, sendo calculada através da relação entre a massa dos grãos retidos em cada peneira e a massa da amostra total; g) a análise química do 
solo aos 20 dias após a colheita do milho-grão, onde foram realizadas amostragens de solo na camada de 0-20 cm, com trado tipo "caneca", perpendicular ao sentido da linha de semeadura, e encaminhadas para análise de acordo com metodologias descritas em Raij et al. (2001); e h) a análise econômica da produção de grãos de feijão com a aplicação de adubação nitrogenada em cobertura, de acordo com a metodologia descrita por Binotti et al. (2009), considerando ser de R\$1.194,91 o valor médio da tonelada de uréia no $2^{\circ}$ semestre de 2010 e o custo de R \$ 30,07 ha-1 para sua aplicação em cobertura (AGRIANUAL, 2010).

Com base na produtividade média de grãos de cada tratamento foram determinados os acréscimos de produtividade proporcionados em relação à testemunha $($ sem N). Calculou-se o valor da produção correspondente àqueles acréscimos de produtividade e respectivas margens bruta de ganho na venda dos grãos de feijão para cada dose de $\mathrm{N}$ utilizada, com base no preço mínimo de $\mathrm{R} \$ 80,00$ a saca de $60 \mathrm{~kg}$ de grãos no estado de São Paulo, estabelecido pelo Programa de Garantia de Preços Mínimos (CONAB, 2010).

Os dados foram submetidos à análise de variância utilizando-se o teste $\mathrm{F}$ ao nível de significância de 5\%. Quando houve significância estatística, as médias foram comparadas por meio do teste de Tukey a 5\% de significância e por regressão polinomial.

\section{Resultados e Discussão}

No feijoeiro semeado em solo com elevada quantidade de palhada produzida pela $B$. ruziziensis não consorciada (12.931 kg ha-1 de massa seca), foi observado sintomas visuais de estiolamento das plântulas de feijoeiro e o aumento no número de dias para o florescimento da cultura (Tabela 1) em relação ao do feijoeiro semeado sobre palhadas resultantes do consórcio milho-grão com $B$. ruziziensis e apenas milho-grão, respectivamente, com $6.343 \mathrm{~kg}$ $\mathrm{ha}^{-1}$ e $6.160 \mathrm{~kg} \mathrm{ha}^{-1}$ de massa seca. Isso significa que o produtor deverá estar atento ao momento de cada estádio da cultura, dependendo do sistema de cultivo empregado, pois afetará diretamente a realização dos tratos culturais. A maior quantidade de palhada apresentada pela forrageira não consorciada, em relação às duas outras formas de produção de palhada, foi consequência da inexistência de competição exercida pela cultura de milho-grão. Porém, a adoção de sistema de produção capaz de gerar conjuntamente grãos e palhada é aquele passível de aceitação pelo produtor.

Borghi e Crusciol (2007) estudando o consórcio de milho-grão e $B$. brizantha, verificaram que ao realizar a adubação de cobertura no milhogrão (90 $\mathrm{kg} \mathrm{ha}^{-1}$ de $\mathrm{N}$ ), com o uso de sulfato de amônio, não houve limitação deste nutriente para as espécies, proporcionando uma produtividade de $8.905 \mathrm{~kg} \mathrm{ha}^{-1}$ de grãos de milho e de $4.266 \mathrm{~kg} \mathrm{ha}^{-1} \mathrm{de}$ matéria seca de $B$. brizantha. Além de obterem-se bons resultados com a produtividade de grãos de milho e de matéria seca com o uso de forrageiras consorciadas, a manutenção do solo estruturado e coberto com palhada é fator chave para que o solo suporte a ação mecânica de fatores externos, como a supressão da ação erosiva das gotas de chuva e da irrigação, dissipando parte da energia do impacto mecânico (BRAIDA et al., 2006), o aumento da velocidade da ciclagem de nutrientes e o aumento das concentrações de carbono orgânico no solo ao longo do tempo (BALBINOT JÚNIOR et al., 2009), reduzindo os riscos de insucesso econômico ao produtor, já que o sistema de semeadura direta, dessa forma, se torna viável e sustentável. 
Tabela 1. Dias para o florescimento após a emergência, teor foliar de nitrogênio total (NT) e produtividade de grãos de feijoeiro cultivar Pérola, conduzido com aplicação de doses de nitrogênio em cobertura, cultivado em sucessão a $B$. ruziziensis, consórcio milho-grão e B. ruziziensis e milho-grão.

\begin{tabular}{|c|c|c|c|c|}
\hline Tratamentos & Florescimento & Teor foliar de NT & Massa de 100 grãos & Produtividade de grãos \\
\hline & ------- dias ------- & ------- g kg-1 $------^{-1}$ & - & -------- kg ha' ${ }^{-1}$ \\
\hline \multicolumn{5}{|l|}{ Sucessão (S) } \\
\hline B. ruziziensis & $45 \mathrm{a}^{1 /}$ & $38 \mathrm{a}$ & 25,8 & $2.143 \mathrm{a}$ \\
\hline Consórcio & $42 \mathrm{~b}$ & $36 \mathrm{ab}$ & 25,2 & $2.319 \mathrm{a}$ \\
\hline Milho-grão & $42 \mathrm{~b}$ & $35 \mathrm{~b}$ & 24,9 & $1.636 \mathrm{~b}$ \\
\hline CV (\%) & 2,5 & 5,5 & 6,5 & 8,6 \\
\hline \multicolumn{5}{|l|}{ Dose de N (D) } \\
\hline $\mathbf{0}$ & 43 & 34 & 24,7 & 1.892 \\
\hline 40 & 43 & 34 & 24,8 & 1.995 \\
\hline 80 & 43 & 36 & 25,4 & 2.007 \\
\hline 120 & 43 & 37 & 25,6 & 2.119 \\
\hline 160 & 43 & 39 & 26,1 & 2.151 \\
\hline CV (\%) & 2,2 & 10,6 & 6,7 & 11,7 \\
\hline \multicolumn{5}{|l|}{ Teste F } \\
\hline $\mathbf{S}$ & $38,79 * * 21$ & $7,06^{*}$ & $1,14^{\mathrm{ns}}$ & $61,62 * *$ \\
\hline D & $0,27^{\text {ns }}$ & $2,87 * 3 /$ & 1,02 ns & $1,72^{\text {ns }}$ \\
\hline$\underline{S} \times \mathbf{D}$ & 1,04 ns & $1,00^{\mathrm{ns}}$ & $0,59^{\mathrm{ns}}$ & $1,05^{\mathrm{ns}}$ \\
\hline
\end{tabular}

${ }^{1 / M e ́ d i a s ~ n a ̃ o ~ s e g u i d a s ~ p e l a ~ m e s m a ~ l e t r a ~ n a ~ c o l u n a ~ d i f e r e m ~ s i g n i f i c a t i v a m e n t e ~ p e l o ~ t e s t e ~ d e ~ T u k e y ~ a ~ 5 \% ~ d e ~ s i g n i f i c a ̂ n c i a . ~}$

${ }^{2 /} \mathrm{ns}$ - não significativo pelo teste $\mathrm{F}$ a $5 \%$ de probabilidade de erro. ${ }^{* *}$ - Significativo pelo teste $\mathrm{F}$ a $1 \%$ de probabilidade de erro. ${ }^{3 / y}=0,0334 \mathrm{x}+33,546 ; \mathrm{R}^{2}=0,96 * *$.

Fonte: Elaboração dos autores.

O teor foliar de NT no florescimento do feijoeiro foi influenciado positivamente pela palhada de $B$. ruziziensis não consorciada, aumentando 7,9\% quando comparada com o observado no feijoeiro cultivado sobre palhada de milho-grão (Tabela 1). Entretanto, não foram verificados sintomas visuais de deficiência de $\mathrm{N}$ nas plantas do feijoeiro, estando os valores encontrados compreendidos na faixa considerada como adequada ao feijoeiro, entre $30 \mathrm{e}$ $50 \mathrm{~g} \mathrm{~kg}^{-1}$ (AMBROSANO et al., 1997).

Quanto à produtividade de grãos, o feijoeiro em sucessão à palhada de $B$. ruziziensis consorciada com milho-grão apresentou rendimento 29,5\% superior ao cultivado em sucessão à palhada de milho-grão, assim como $23,7 \%$ superior quando a cultura antecessora foi apenas a $B$. ruziziensis em comparação a utilização de milho-grão (Tabela 1). A maior produtividade de grãos sobre a palhada de $B$. ruziziensis como cultura antecessora, pode estar na melhor cobertura da superfície do solo proporcionado pela forrageira. A cobertura superficial do solo, determinada de acordo com metodologia de Laflen, Amemiya e Hintz (1981), foi de $100 \%$ e de $93 \%$ para $B$. ruziziensis não consorciada e em conjunto com a palhada do milho-grão, respectivamente. No sistema de cultivo em sucessão a palhada de milhogrão, a cobertura superficial do solo foi de apenas $73 \%$.

Outros fatores como a liberação de $\mathrm{N}$ pela decomposição da palhada de B. ruziziensis, identificada pelo aumento no teor foliar de NT no florescimento (Tabela 1) e pela não resposta ao uso da adubação nitrogenada em cobertura (Figura 1), podem ter influenciado no aumento da produtividade de grãos nos sistemas de cultivo que utilizaram a $B$. ruziziensis como cultura antecessora. 
Figura 1. Desdobramento da interação referente à produtividade de grãos de feijão cultivar Pérola, conduzido com aplicação de diferentes doses de nitrogênio em cobertura, cultivado em sucessão a B. ruziziensis, consórcio milho-grão e B. ruziziensis e milho-grão.

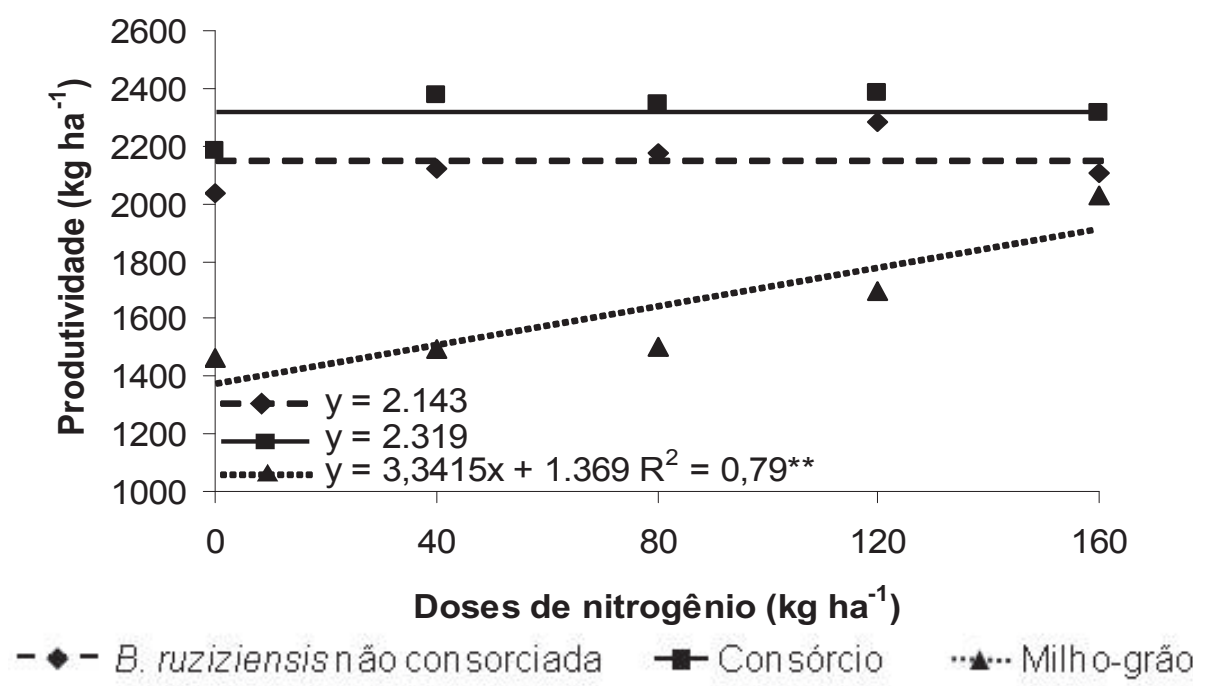

Fonte: Elaboração dos autores.

No caso do feijoeiro cultivado em palhada do milho-grão não consorciado, observou-se resposta positiva da leguminosa ao fornecimento do $\mathrm{N}$ em cobertura (Figura 1). A elevada relação $\mathrm{C} / \mathrm{N}$ da palhada de milho-grão e a menor porcentagem de cobertura do solo podem ter contribuído para a resposta ao $\mathrm{N}$ em cobertura no feijoeiro. De forma linear, foi verificado que cada $\mathrm{kg}$ de $\mathrm{N}$ aplicado, houve aumento na produtividade de $3,34 \mathrm{~kg}$ de grãos de feijoeiro até a aplicação de $160 \mathrm{~kg}$ ha $^{-}$ 1, sem atingir o teto máximo de produtividade. Lopes et al. (2004b) atribuem a imobilização do $\mathrm{N}$ quando a relação $\mathrm{C} / \mathrm{N}$ da palhada for acima de $30 / 1$, justificando a resposta positiva do feijoeiro ao fornecimento do $\mathrm{N}$ em cobertura quando cultivado em sucessão ao milho-grão. Silveira et al. (2001) analisando o comportamento do feijoeiro cultivado em diferentes rotações, observaram que as menores produtividades foram obtidas nas rotações que apresentaram o milho-grão como antecessora, semelhante ao que ocorreu no presente trabalho. Soratto, Carvalho e Arf (2004), obtiveram a produtividade máxima de $2.309 \mathrm{~kg} \mathrm{ha}^{-1}$ de grãos de feijão em sucessão ao milho-grão, com a aplicação de $182 \mathrm{~kg} \mathrm{ha}^{-1}$ de $\mathrm{N}$ no sistema de semeadura direta.
Quanto ao rendimento de grãos por todas as peneiras comerciais utilizadas na avaliação, observou-se que a adubação nitrogenada não influenciou os resultados (Tabela 2). Houve diminuição na porcentagem de grãos de feijão retidos no fundo do conjunto de peneiras no feijoeiro cultivado sobre palhada de $B$. ruziziensis, em relação ao observado em feijoeiro cultivado sobre palhada de milho-grão. A baixa população final de plantas no sistema de cultivo em sucessão a B. ruziziensis, devido ao mau estabelecimento das plântulas, em função da quantidade de palhada produzida nesse sistema (12.931 kg ha-1 de massa seca) pode ter favorecido o melhor desenvolvimento dos grãos através do sistema de compensação de espaços que a cultura possui, mas sem alterar a massa de 100 grãos (Tabela 1). Além disso, maior quantidade de grãos foi retida na peneira número 13 , no feijoeiro colhido sobre a sucessão com $B$. ruziziensis não consorciada em relação ao do colhido na sucessão com milho-grão, contribuiu para a obtenção de $68,8 \%$ de renda no somatório das peneiras acima do número 12 (Figura 2). A peneira número 12 é a adotada pelas empacotadoras de grãos de feijão, as quais oferecem uma gratificação financeira (ágio) 
para fornecedores que apresentam um produto com renda acima de 65\% (FARINELLI, 2003), caracterizando-se como grãos graúdos.

Quanto à análise química do solo realizada ao final da colheita do feijoeiro na camada $0-20 \mathrm{~cm}$, não houve diferenças significativas entre as palhadas estudadas em função da dose de $\mathrm{N}$ em cobertura (Tabela 3). Justifica-se este resultado por se tratar de um sistema de semeadura direta em implantação. Para o pH do solo, a palhada de B. ruziziensis não consorciada proporcionou a manutenção do valor verificado no início da implantação dos tratamentos, possivelmente pelo pastejo não ter sido realizado e assim não houve extração de bases do solo, enquanto que nas demais formas de produção de palhada houve pequeno aumento na acidez do solo, provavelmente pelo uso de fertilizante nitrogenado na cultura do milho que antecedeu o feijoeiro e pela extração de bases na colheita dos grãos de milho (Tabela 3).

Tabela 2. Valores de F, níveis de significância e coeficiente de variação (CV) da porcentagem de grãos de feijão retidos nas peneiras de beneficiamento em feijoeiro conduzido com aplicação de diferentes doses de nitrogênio em cobertura, cultivado em sucessão a B. ruziziensis, consórcio milho-grão e B. ruziziensis e milho-grão.

\begin{tabular}{|c|c|c|c|c|c|c|}
\hline Tratamentos & Fundo & Peneira 11 & Peneira 12 & Peneira 13 & Peneira 14 & Peneiras $>12$ \\
\hline Sucessão (S) & $12,05 * 1 /$ & $3,26^{\mathrm{ns}}$ & $0,59^{\mathrm{ns}}$ & $8,17 *$ & $2,95^{\mathrm{ns}}$ & $7,73 *$ \\
\hline CV (\%) & 8,6 & 16,6 & 7,7 & 12,7 & 31,7 & 8,4 \\
\hline Dose de N (D) & 1,24 ns & $0,27^{\mathrm{ns}}$ & $1,00 \mathrm{~ns}$ & 0,99 ns & 0,63 ns & $0,63^{\mathrm{ns}}$ \\
\hline CV (\%) & 9,2 & 8,1 & 5,7 & 7,6 & 15,2 & 6,0 \\
\hline$\overline{S \times D}$ & $1,32^{\mathrm{ns}}$ & $0,77^{\mathrm{ns}}$ & $0,33^{\text {ns }}$ & $0,86^{\mathrm{ns}}$ & $2,88^{*}$ & 0,94 ns \\
\hline
\end{tabular}

${ }^{1 / \mathrm{ns}}$ - não significativo pelo teste $\mathrm{F}$ a $5 \%$ de probabilidade de erro. * - Significativo pelo teste $\mathrm{F}$ a $5 \%$ de probabilidade de erro.

Fonte: Elaboração dos autores.

Figura 2. Renda de beneficiamento de grãos de feijão cultivar Pérola, conduzido com aplicação de diferentes doses de nitrogênio em cobertura, cultivado em sucessão a B. ruziziensis, consórcio milho-grão e $B$. ruziziensis e milhogrão. Médias não seguidas pela mesma letra nas peneiras diferem significativamente pelo teste de Tukey a $5 \%$ de significância.

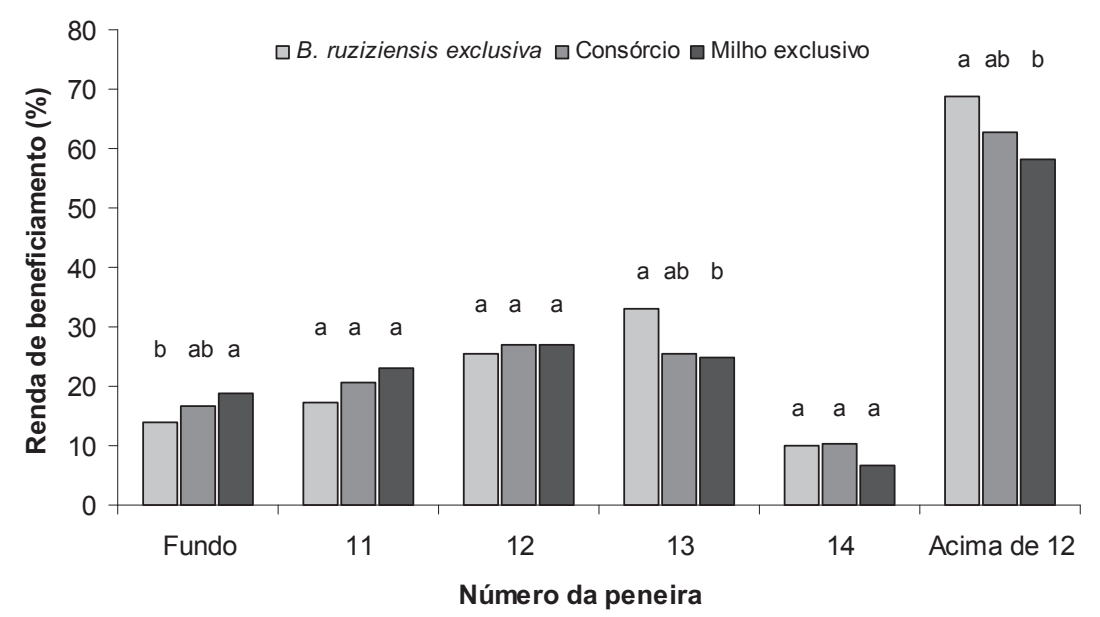

Fonte: Elaboração dos autores. 
Adubos amídicos e amoniacais têm ação acidificante no solo, havendo no processo de nitrificação a liberação de íons $\mathrm{H}^{+}$(TAIZ; ZEIGER, 2004). Dessa forma, a adubação nitrogenada feita com uréia ( $\mathrm{N}$ amídico) poderá contribuir para a redução no $\mathrm{pH}$ e aumento no teor de $\mathrm{H}+\mathrm{Al}$ (CANTARELLA, 2007). Barbosa Filho, Fageria e Silva (2005) relataram que após três anos de cultivo com feijoeiro Pérola no inverno, a aplicação de doses de $\mathrm{N}$ em cobertura (0 a $150 \mathrm{~kg} \mathrm{ha}^{-1}$ ), via uréia, provocou a redução do $\mathrm{pH}$ de 5,7 para 5,4 na camada de 0-20 cm.

A extração de bases pela colheita dos grãos de milho (10.828 kg ha-1 de grãos no tratamento sem consórcio e $11.038 \mathrm{~kg} \mathrm{ha}^{-1}$ de grãos no tratamento com consórcio de $B$. ruziziensis) deve ter contribuído para a redução na saturação por bases (V\%). (Tabela 3). Silveira et al. (2010), trabalhando com oito espécies de plantas de cobertura antecedendo a cultura do feijoeiro, obtiveram como rendimentos médios anuais de massa seca da parte aérea das coberturas, $11,0 \mathrm{t}$ de $B$. brizantha; 4,3 t de consorciação do milho-grão com $B$. brizantha; 3,6 $\mathrm{t}$ de guandu; 6,6 t de milheto; 8,2 t de mombaça; 4,6 t de sorgo-grão; 2,6 t de estilosantes; e, 6,9 t de crotalária. Quatro anos após o início dos sistemas de cultivo, os autores verificaram que o $\mathrm{pH}$ do solo foi maior na área com $B$. brizantha não consorciada $(5,84)$ do que na área com consórcio de milhogrão e $B$. brizantha $(5,58)$ até a profundidade de $20 \mathrm{~cm}$, com destaque para a diferença ainda maior encontrada na camada superficial de solo $(0-5 \mathrm{~cm})$.

Quanto ao teor de potássio inicial no solo que era 4,4 $\mathrm{mmol}_{\mathrm{c}} \mathrm{dm}^{-3}$ aumentou para 6,0 $\mathrm{mmol}_{\mathrm{c}} \mathrm{dm}^{-3}$ no solo amostrado ao final da colheita do feijoeiro cultivado em sucessão à palhada de $B$. ruziziensis não consorciada. Nas demais formas de produção de palhada os valores ficaram abaixo do teor inicial
(Tabela 3). Isso, provavelmente ocorreu devido à elevada capacidade de aprofundamento do sistema radicular da $B$. ruziziensis trazendo para a superfície do solo quantidades elevadas de K. Dessa forma, a ciclagem dos restos culturais permite a elevação dos teores deste elemento na camada 0-20 cm. Torres e Pereira (2008), na implantação do sistema de semeadura direta, verificaram maior acúmulo de potássio em gramíneas, com $55 \%$ da liberação deste elemento pela palhada de $B$. brizantha nos primeiros 42 dias após dessecação.

Do ponto de vista econômico, a dose de $\mathrm{N}$ correspondente à maior produtividade de grãos muitas vezes não é a mais rentável (BINOTTI et al., 2009). Como a palhada de B. ruziziensis, pode ter fornecido quantidades significativas de nutrientes, principalmente de $\mathrm{N}$, não houve margem bruta de ganho na venda dos grãos de feijão para a maioria das doses de $\mathrm{N}$ avaliadas em cobertura (Tabela 4). No consórcio, apenas com a dose de $40 \mathrm{~kg} \mathrm{ha}^{-1} \mathrm{de}$ $\mathrm{N}$ em cobertura houve margem bruta de ganho na venda dos grãos de feijão, sendo positiva em relação ao tratamento sem aplicação de N.

$\mathrm{Na}$ sucessão com milho-grão exclusivo, onde o aumento da produtividade pela aplicação de $\mathrm{N}$ em cobertura foi crescente (Figura 2), a única margem bruta positiva de ganho na venda dos grãos de feijão foi alcançada com o uso da dose de $160 \mathrm{~kg} \mathrm{ha}^{-1}$ de $\mathrm{N}$ (Tabela 4). Isto demonstra ser indispensável a utilização de elevadas doses de $\mathrm{N}$ em cobertura para o feijoeiro cultivado em sucessão ao milho-grão. Binotti et al. (2009) verificaram que a aplicação de elevadas doses de $\mathrm{N}$ (150 e $\left.200 \mathrm{~kg} \mathrm{ha}^{-1}\right)$, totalmente em semeadura ou $1 / 3$ na semeadura e $2 / 3$ em cobertura no estádio $\mathrm{V}_{4-4}$ do feijoeiro, não foram as que proporcionaram as maiores margens brutas de ganho, mas sim a aplicação de doses menores (50 $\left.\mathrm{kg} \mathrm{ha}^{-1}\right)$. 
Tabela 3. Análise química do solo na camada $0-20 \mathrm{~cm}$, após cultivo do feijoeiro cultivar Pérola, conduzido com aplicação de diferentes doses de nitrogênio em cobertura, em sucessão a $B$. ruziziensis, consórcio milho-grão e $B$. ruziziensis e milho-grão.

\begin{tabular}{|c|c|c|c|c|c|c|c|c|c|c|}
\hline \multirow{2}{*}{ Tratamentos } & pH & M.O. & P-resina & $\mathbf{K}$ & $\mathbf{C a}$ & Mg & $\mathbf{H}+\mathbf{A l}$ & SB & CTC & $\mathbf{V}$ \\
\hline & \multicolumn{2}{|c|}{$-\mathrm{CaCl}_{2}---\mathrm{g} \mathrm{dm}^{-3}--$} & $--\mathbf{m g ~ d m}^{-3}-$ & \multicolumn{6}{|c|}{--------------------------- $\mathrm{mmol}_{\mathrm{c}} \mathrm{dm}^{-3}$------------------------ } & ---- \%---- \\
\hline \multicolumn{11}{|l|}{ Sucessão (S) } \\
\hline B. ruziziensis & $5,2 \mathrm{a}^{1 /}$ & 19 & 55 & $6,0 \mathrm{a}$ & 27 & 11 & $34 \mathrm{~b}$ & 44,4 & 78,0 & $57 \mathrm{a}$ \\
\hline Consórcio & $5,0 \mathrm{~b}$ & 20 & 54 & $4,1 \mathrm{~b}$ & 27 & 11 & $40 \mathrm{a}$ & 41,8 & 81,5 & $51 \mathrm{ab}$ \\
\hline Milho-grão & $4,9 \mathrm{~b}$ & 20 & 55 & $3,6 \mathrm{~b}$ & 24 & 10 & $41 \mathrm{a}$ & 38,1 & 79,5 & $47 \mathrm{~b}$ \\
\hline CV (\%) & 3,2 & 8,6 & 20,8 & 10,4 & 15,9 & 16,9 & 8,7 & 14,1 & 8,5 & 9,2 \\
\hline \multicolumn{11}{|l|}{ Dose de N (D) } \\
\hline $\mathbf{0}$ & 5,1 & 19 & 46 & 4,6 & 26 & 11 & 38 & 41,8 & 79,6 & 53 \\
\hline 40 & 5,0 & 20 & 52 & 4,8 & 26 & 11 & 39 & 41,7 & 80,2 & 52 \\
\hline 80 & 5,0 & 19 & 58 & 4,1 & 26 & 10 & 38 & 39,9 & 78,3 & 51 \\
\hline 120 & 5,1 & 20 & 58 & 4,8 & 27 & 11 & 38 & 43,2 & 81,0 & 53 \\
\hline 160 & 5,0 & 20 & 60 & 4,5 & 26 & 10 & 39 & 40,6 & 79,2 & 51 \\
\hline CV (\%) & 3,2 & 5,8 & 12,2 & 15,3 & 9,9 & 13,2 & 6,7 & 8,2 & 5,2 & 5,6 \\
\hline \multicolumn{11}{|l|}{ Teste F } \\
\hline $\mathbf{S}$ & $12,72 * 2$ & $0,24 \mathrm{~ns}$ & $0,04 \mathrm{~ns}$ & $108,86^{* *}$ & $2,92 \mathrm{~ns}$ & $0,42 \mathrm{~ns}$ & $23,19 * *$ & $4,51 \mathrm{~ns}$ & $0,98 \mathrm{~ns}$ & $14,77 *$ \\
\hline D & $0,55 \mathrm{~ns}$ & $1,19 \mathrm{~ns}$ & $6,65 * *$ & $1,48 \mathrm{~ns}$ & $0,70 \mathrm{~ns}$ & $0,83 \mathrm{~ns}$ & $0,20 \mathrm{~ns}$ & $1,25 \mathrm{~ns}$ & $0,54 \mathrm{~ns}$ & $1,35 \mathrm{~ns}$ \\
\hline$S \times D$ & $0,32 \mathrm{~ns}$ & $1,36 \mathrm{~ns}$ & $1,71 \mathrm{~ns}$ & $0,63 \mathrm{~ns}$ & $1,32 \mathrm{~ns}$ & $0,88 \mathrm{~ns}$ & $2,11 \mathrm{~ns}$ & $1,02 \mathrm{~ns}$ & $1,90 \mathrm{~ns}$ & $0,97 \mathrm{~ns}$ \\
\hline
\end{tabular}

${ }^{1 /}$ Médias não seguidas pela mesma letra na coluna diferem significativamente pelo teste de Tukey a 5\% de significância.

${ }^{2 /} \mathrm{ns}$ - não significativo pelo teste $\mathrm{F}$ a $5 \%$ de probabilidade de erro. ${ }^{*}$ - Significativo pelo teste $\mathrm{F}$ a $5 \%$ de probabilidade de erro. ** - Significativo pelo teste $\mathrm{F}$ a $1 \%$ de probabilidade de erro.

Fonte: Elaboração dos autores.

Tabela 4. Análise econômica da produção de grãos de feijão, conduzido com aplicação de diferentes doses de nitrogênio em cobertura, em sucessão a $B$. ruziziensis, consórcio milho-grão e $B$. ruziziensis e milho-grão.

\begin{tabular}{|c|c|c|c|c|c|c|}
\hline \multicolumn{2}{|c|}{ Tratamentos } & \multirow{2}{*}{$\begin{array}{l}\text { Produtividade } \\
\text { de grãos }\end{array}$} & \multirow{2}{*}{$\begin{array}{l}\text { Acréscimo na } \\
\text { produtividade } \\
\text { de grãos }\end{array}$} & \multirow{2}{*}{$\begin{array}{l}\text { Acréscimo no valor de } \\
\text { produção }(\mathrm{R} \$ \mathbf{8 0 , 0 0})^{1 /}\end{array}$} & \multirow{2}{*}{$\begin{array}{c}\text { Custo da } \\
\text { aplicação }^{2 /}\end{array}$} & \multirow{2}{*}{$\begin{array}{l}\text { Margem bruta de } \\
\text { ganho (R\$ 80,00) }\end{array}$} \\
\hline Sucessão & Dose de N & & & & & \\
\hline & \multicolumn{3}{|c|}{ 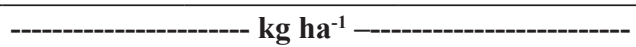 } & \multicolumn{3}{|c|}{ - } \\
\hline \multirow{5}{*}{ B. ruziziensis } & $\mathbf{0}$ & 2034 & - & - & - & - \\
\hline & 40 & 2117 & 83 & 110,6 & 136,3 & $-25,6$ \\
\hline & 80 & 2177 & 143 & 190,1 & 242,5 & $-52,4$ \\
\hline & 120 & 2285 & 251 & 334,3 & 348,7 & $-14,5$ \\
\hline & 160 & 2106 & 72 & 95,7 & 454,9 & $-359,2$ \\
\hline \multirow{5}{*}{ Consórcio } & $\mathbf{0}$ & 2180 & - & - & - & - \\
\hline & 40 & 2376 & 195 & 260,5 & 136,3 & 124,2 \\
\hline & 80 & 2343 & 163 & 216,6 & 242,5 & $-25,9$ \\
\hline & 120 & 2381 & 201 & 267,7 & 348,7 & $-81,0$ \\
\hline & 160 & 2316 & 136 & 181,3 & 454,9 & $-273,6$ \\
\hline \multirow{5}{*}{ Milho-grão } & $\mathbf{0}$ & 1463 & - & - & - & - \\
\hline & 40 & 1493 & 30 & 40,0 & 136,3 & $-96,3$ \\
\hline & 80 & 1503 & 40 & 53,4 & 242,5 & $-189,1$ \\
\hline & 120 & 1693 & 230 & 307,1 & 348,7 & $-41,6$ \\
\hline & 160 & 2031 & 568 & 757,5 & 454,9 & 302,6 \\
\hline
\end{tabular}

${ }^{1 /}$ Com base no preço médio de $\mathrm{R} \$ 80,00$ por saca de $60 \mathrm{~kg}$ de grãos de feijão carioca (CONAB, 2010).

${ }^{2}$ Preço da uréia (agosto de 2010) $=\mathrm{R} \$ 1.194,91 \mathrm{t}^{-1} \mathrm{e}$ da aplicação da adubação de cobertura $=\mathrm{R} \$ 30,07$ ha $^{-1}$ (AGRIANUAL, 2010).

Fonte: Elaboração dos autores. 


\section{Conclusões}

Em sucessão ao milho-grão, a produtividade de grãos de feijão é influenciada positivamente pela adubação nitrogenada, sendo economicamente viável apenas quando fornecido $160 \mathrm{~kg} \mathrm{ha}^{-1}$ de nitrogênio.

O uso do consórcio entre milho-grão e $B$. ruziziensis é a melhor opção quando o feijoeiro é semeado em sucessão, visando a adoção do sistema de semeadura direta em regiões com inverno seco.

A palhada de $B$. ruziziensis promove elevação na percentagem de grãos de feijão com classificação em peneira maior que 12 , redução no processo de acidificação do solo e maior aporte de $\mathrm{K}^{+}$na camada superficial do solo.

\section{Agradecimentos}

À Coordenação de Aperfeiçoamento de Pessoal de Nível Superior - CAPES, pela concessão da bolsa de pesquisa.

\section{Referências}

ANUÁRIO DA AGRICULTURA BRASILEIRA AGRIANUAL. Feijão. São Paulo: Agra FNP Pesquisas Ltda., 2010. 520 p.

AMBROSANO, E. J.; WUTKE, E. B.; BULISANI, E. A.; CANTARELlA, H. Feijão. In: RAIJ, B. van; CANTARELlA, H.; QUAGGIO, J. A.; FURLANI, A. M. C. Recomendação de adubação e calagem para o Estado de São Paulo. 2. ed. Campinas: IAC, p. 194-195, 1997. (Boletim técnico, 100).

BALBINOT JUNIOR, A. A.; MORAES, A.; VEIGA, M.; PELISSARI, A.; DIECKOW, J. Integração lavourapecuária: intensificação de uso de áreas agrícolas. Ciência Rural, Santa Maria, v. 39, n. 6, p. 1925-1933, 2009.

BARBOSA FILHO, M. P.; FAGERIA, N. K.; SILVA, O. F. da. Fontes, doses e parcelamento da adubação nitrogenada em cobertura para feijoeiro comum irrigado. Ciência e Agrotecnologia, Lavras, v. 29, n. 1, p. 69-76, 2005.

BATAGLIA, O. C.; FURLANI, A. M. C.; TEIXEIRA, J. P. F.; FURLANI, P. R.; GALLO, J. R. Métodos de análise química de plantas. Campinas: Instituto Agronômico, 1983. 48 p. (Boletim técnico, 78).
BINOTTI, F. F. S.; ARF, O.; SÁ, M. E.; BUZETTI, S.; ALVAREZ, A. C.; KAMIMURA, K. M. Fontes, doses e modo de aplicação de $\mathrm{N}$ em feijoeiro no sistema plantio direto. Bragantia, Campinas, v. 68 , n. 2, p. 473-481, 2009.

BORGHI, E.; CRUSCIOL, C. A. C. Produtividade de milho, espaçamento e modalidade de consorciação com Brachiaria brizantha em sistema plantio direto. Pesquisa Agropecuária Brasileira, Brasília, v. 42, n. 2, p. 163-171, 2007.

BRAIDA, J. A.; REICHERT, J. M.; VEIGA, M.; REINERT, D. J. Resíduos vegetais na superfície e carbono orgânico do solo e suas relações com a densidade máxima obtida no ensaio proctor. Revista Brasileira de Ciência do Solo, Viçosa, v. 30, n. 4, p. 605-614, 2006.

CANTARELLA, H. Nitrogênio. In: NOVAIS, R. F.; ALVAREZ, V. V. H.; BARROS, N. F.; FONTES, R. L. F.; CANTARUTTI, R. B.; NEVES, J. C. L. (Ed.). Fertilidade do solo. Gramado: SBCS, 2007. p. 375-470.

COMPANHIA NACIONAL DE ABASTECIMENTO - CONAB. Política de garantia de preços mínimos. Disponível em: <http://consultaweb.conab.gov.br/ consultas/consultaPgpm.do? method=acaoCarregar Consulta $>$. Acesso em: 10 set. 2010.

FARINELLI, R. Resposta do feijoeiro (Phaseolus vulgaris L.) à adubação nitrogenada de cobertura em dois sistemas de manejo de solo. 2003. Dissertação (Mestrado em Agronomia) - Faculdade de Ciências Agronômicas. Universidade Estadual Paulista, Botucatu.

FERNÁNDEZ, F.; GEPTS, P.; LÓPEZ, M. Etapas de desarrollo en la planta del fríjol (Phaseolus vulgaris L.). In: LÓPEZ, M.; FERNÁNDEZ, F.; SCHOONHOVEN, A. van. Fríjol: investigación y producción. Cali: CIAT, 1985. p. 61-78.

FREIXO, A. A.; MACHADO, P. L. O. A.; GUIMARÃES, C. M.; SILVA, C. A.; FADIGAS, F. S. Estoques de carbono e nitrogênio e distribuição de frações orgânicas de Latossolo do cerrado sob diferentes sistemas de cultivo. Revista Brasileira de Ciência do Solo, Viçosa, v. 26, n. 2, p. 425-434, 2002.

LAFLEN, J. M.; AMEMIYA, A.; HINTZ, E. A. Measuring crop residues cover. Journal of Soil and Water Conservation, Ankeny, v. 36, n. 6, p. 341-343, 1981.

LOPES, A. S.; PAVANI, L. C.; CORÁ, J. E.; ZANINI, J. R.; MIRANDA, H. A. Manejo da irrigação (tensiometria e balanço hídrico climatológico) para a cultura do feijoeiro em sistemas de cultivo direto e convencional. Engenharia Agrícola, Jaboticabal, v. 24, n. 1, p. 89-100, 2004a. 
LOPES, A. S; WIETHOLTER, S.; GUILHERME, L. R. G.; SILVA, C. A. S. Sistema plantio direto: bases para o manejo da fertilidade do solo. São Paulo: ANDA, 2004b. $110 \mathrm{p}$.

RAIJ, B.; ANDRADE, J. C.; CANTARELLA, H.; QUAGGIO, J. A. (Ed.). Análise química para avaliação de fertilidade de solos tropicais. Campinas: Instituto Agronômico, 2001. 285 p.

SILVA, I. F.; MIELNICZUK, J. Ação do sistema radicular de plantas na formação e estabilização de agregados do solo. Revista Brasileira de Ciência do Solo, Viçosa, v. 20, n. 1, p. 113-117, 1997.

SILVA, P. C. G.; FOLONI, J. S. S.; FABRIS, L. B.; TIRITAN, C. S. Fitomassa e relação $\mathrm{C} / \mathrm{N}$ em consórcios de sorgo e milho com espécies de cobertura. Pesquisa Agropecuária Brasileira, Brasília, v. 44, n. 11, p. 15041512, 2009.

SILVEIRA, P. M.; SILVA, O. F.; STONE, L. F.; SILVA, J. G. Efeitos do preparo do solo, plantio direto e de rotações de culturas sobre o rendimento e a economicidade do feijoeiro irrigado. Pesquisa Agropecuária Brasileira, Brasília, v. 36, n. 2, p. 257-263, 2001.
SILVEIRA, P. M.; CUNHA, P. C. R.; STONE, L. F.; SANTOS, G. G. Atributos químicos de solo cultivado com diferentes culturas de cobertura. Pesquisa Agropecuária Tropical, Goiânia, v. 40, n. 2, p. 283-290, 2010.

SORATTO, R. P.; CARVAlHO, M. A. C.; ARF, O. Teor de clorofila e produtividade do feijoeiro em razão da adubação nitrogenada. Pesquisa Agropecuária Brasileira, Brasília, v. 39, n. 9, p. 895-901, 2004.

TAIZ, L.; ZEIGER, E. Fisiologia vegetal. 3. ed. Porto Alegre: Artmed, 2004. 722 p.

TORRES, J. L. R.; PEREIRA, M. G.; ANDRIOLI, I.; POLIDORO, J. C.; FABIAN, A. J. Decomposição e liberação de nitrogênio de resíduos culturais de plantas de cobertura em um solo de cerrado. Revista Brasileira de Ciência do Solo, Viçosa, v. 29, n. 4, p. 609-618, 2005.

TORRES, J. L. R.; PEREIRA, M. G. Dinâmica do potássio nos resíduos vegetais de plantas de cobertura no Cerrado. Revista Brasileira de Ciência do Solo, Viçosa, v. 32, n. 4, p. 1609-1618, 2008. 
